\title{
A Semana de Arte Moderna de 1922 e o Modernismo Brasileiro: atualização cultural e "primitivismo" artístico*
}

Evando Nascimento ${ }^{a}$

\begin{abstract}
Resumo
Noventa anos depois da Semana de Arte Moderna de 1922, ocorrida em São Paulo, este texto discute suas relações com as vanguardas europeias, bem como alguns de seus desdobramentos. São destacados o projeto estético e o projeto político que orientaram o modernismo brasileiro. Finalmente, expõe-se o vínculo entre uma das vertentes do movimento modernista, a Antropofagia, e o "primitivismo" estético e cultural europeu, em movimentos como Fauvismo e Dada.
\end{abstract}

Palavras-chave: Semana de 22, Mário de Andrade, Oswald de Andrade, Antropofagia, Primitivismo.

\footnotetext{
* Texto de uma conferência pronunciada em 13 de maio de 2012, em homenagem aos 90 anos da Semana de Arte Moderna no Brasil, no Centre de Recherches sur les Pays Lusophones (CREPAL), na Université Sorbonne Nouvelle, Paris 3 , a convite da professora titular Jacqueline Penjon.
}

\footnotetext{
a Universidade Federal de Juiz de Fora, evandobn@uol.com.br
} 
São Paulo! comoção de minha vida... Galicismo a berrar nos desertos da América!

Mário de Andrade, Pauliceia desvairada

Iniciarei por meio de um breve comentário sobre o título proposto "A Semana de Arte Moderna de 1922 e o Modernismo brasileiro: Atualização cultural e 'primitivismo' artístico". O que aqui nomeio como Modernismo brasileiro constitui um amplo e bastante complexo movimento, que tem seus primeiros sinais nos anos de 1912 e 1917, atingindo seu marco fundamental em 1922, com a chamada Semana de Arte Moderna, realizada nos dias 15, 17 e 19 de fevereiro em São Paulo, perfazendo agora, portanto, 90 anos. Em seguida, vêm os desdobramentos da Semana, com revistas e manifestos vanguardistas, seguindo diferentes orientações. Constitui uma das vertentes mais relevantes do movimento modernista aquela inaugurada pelo Manifesto Antropófago, de Oswald de Andrade, e que ficou conhecida como Antropofagia, a partir de 1928. Para a formulação de seu ideário antropófago, Oswald decerto tirou proveito dos diversos "primitivismos" do início do século XX na Europa, entre eles, o do Manifeste Cannibale Dada e da revista Cannibale, do dadaísta Francis Picabia, ambos de 1920.

Antes de continuar, uma observação prévia. Como hoje bem se sabe, o país chamado Brasil e sua respectiva cultura são uma invenção histórica de pelo menos um povo europeu: os portugueses. Pelo menos um, mas outros também foram responsáveis pelo reconhecimento da existência histórica da colônia lusitana e, posteriormente, da nação independente, tais como os franceses, os holandeses, os espanhóis e, depois do século XVIII, os ingleses, os alemães e os demais povos da Europa dita ocidental. Antes da chegada dos portugueses em 1500, com a esquadra marítima de Pedro Álvares Cabral, nada havia que se pudesse comparar às nações modernas de tipo ocidental. Havia, sim, inúmeras culturas e povos espalhados em tribos e comunidades por toda a extensão do território geopolítico que compreende o hoje assim nomeado Brasil. Designação esta bem portuguesa a partir do termo pau-brasil; pau, madeira que tem a cor da brasa, e que servia para tingir, constituindo a primeira forma de exploração econômica do território invadido. O país que emergirá como nação relati- 
1 Uma boa introdução, embora não isenta de críticas ao colonialismo nas Américas e em muitas outras partes do globo, é a do livro de Marc Ferro, Histoire des colonisations: des conquêtes aux indépendances XIIIe.-XXe. Siècle (1994).

2 A despeito das muitas diferenças de contexto e de organização, a Semana de Arte Moderna de 1922, no Brasil, pode ser comparada ao Armory Show (Exposição do Arsenal), que ocorreu em 1913 em Nova York, numa combinação da produção de vanguarda europeia e da produção artística americana, com obras de pintura, escultura e arte decorativa. $\mathrm{O}$ evento ficou na história como o primeiro contato do grande público americano com a arte moderna europeia. vamente independente em 1922 foi o resultado de uma longa e renhida luta dos portugueses para se apossar e explorar o território supostamente "descoberto" ou "achado" por Cabral e sua frota, quando seguiam rumo às Índias orientais.

A luta para a conquista da terra se deu em dois fronts, com inúmeros cruzamentos e muitas encruzilhadas. Por um lado, era preciso submeter os residentes autóctones, os chamados "índios", que englobavam uma miríade de povos e culturas. Essa sujeição do outro nativo, dito "primitivo", foi obtida por meio de todas as formas de sevícia: espoliação, assassinato, tentativa de escravização, em suma, ao longo de um amplo genocídio, que incluía as doenças trazidas nas embarcações e a assimilação por miscigenação 1 . Por outro lado, os portugueses precisavam conter a concorrência de outros povos europeus, que disputavam a posse da colônia, notadamente os franceses, os holandeses e os espanhóis. Dos franceses ficou bastante conhecida a empreitada malsucedida da implantação, no território onde hoje se situa a cidade do Rio de Janeiro, entre 1555 e 1567, de uma France Antarctique, cujo nome diz tudo. Esse episódio das invasões francesas nas Américas era desconhecido fora do Brasil até o surgimento do livro de Jean-Cristophe Rufin, Rouge Brésil (2003), título de múltiplas conotações coloniais.

\section{A Semana de Arte Moderna de 1922}

O grande movimento de modernização da cultura brasileira, promovido inicialmente por intelectuais e artistas na cidade de São Paulo, tem como um de seus marcos iniciais a exposição de pintura de Anita Malfatti em 1917; como marco de ruptura, a Semana de Arte Moderna de $1922^{2}$ e, como marco terminal possível, o ano de 1945, quando o panorama cultural começa a ganhar nova configuração.

Há um consenso entre os estudiosos quanto a indicar o aspecto desolador da cultura brasileira na passagem do século XIX para o século XX. Excetuados alguns poucos nomes representativos que antecedem o Modernismo, como os autores Lima Barreto e Euclides da Cunha (cujo Os Sertões se tornou uma referência universal, traduzido em diversos idiomas, inclusive em francês, pelas edições Métailié com o título de Hautes terres: La Guerre de Canudos - 2012), o que se tem é uma produção 
3 Uma publicação recente história muito bem os fatos em torno da Semana, sem, todavia, propor uma interpretação inovadora, constituindo antes um inventário jornalístico do evento. Trata-se do livro de Marcos Augusto Gonçalves. 1922: a semana que não terminou (2012).

4 Cf. Mário da Silva Brito. História do modernismo brasileiro: Antecedentes da Semana de Arte Moderna (1978, p. 40-42). cultural bastante decadente. No plano literário, sobrevivem as duas estéticas herdadas do final do século XIX: o Simbolismo e o Parnasianismo (Le Parnasse).

Todavia, atentando-se para o palco dos acontecimentos que interessam, encontravam-se, já na primeira década do século, a cidade e o estado de São Paulo em plena transformação. Seja pelo grande fluxo imigratório europeu, derivado da necessidade de cobrir a demanda de mão de obra no setor agrícola, seja pela industrialização incipiente permitida pelo acúmulo de capital dessa mesma agricultura, São Paulo se destacava do resto do país, inclusive da Capital Federal, na época, o Rio de Janeiro. Seu alto grau de transformação econômica implicava outro tanto de alteração no plano social, com o advento da burguesia industrial, do proletariado a ela vinculado e das classes médias em formação.

É nesse quadro cultural, político e social que se formam e começam a atuar os intelectuais e artistas do grupo que promoverá a Semana de Arte Moderna de 1922 de São Paulo. A história do Modernismo começa no ponto em que algumas de suas figuras passam a ter contato direto ou indireto com as novas informações artísticas do início do século na Europa e, importando-as para o Brasil, provocam as mais diversas reações no meio cultural.

Nesse sentido, a história da Semana e do Modernismo é tanto a história da produção de suas obras representativas quanto a história da recepção dessa mesma criação. ${ }^{3} \mathrm{O}$ fato de a I Exposição de Arte Moderna de Anita Malfatti, em 1917, ser tomada como marco de articulação do movimento se explica por ter sido apenas nesse instante que um conjunto de obras sintonizadas com a modernidade europeia provocou uma resposta pública no Brasil. A própria Anita, voltando dos estudos em Berlim, já tinha realizado em 1914 uma exposição com pinturas de cunho expressionista. Mas, excetuando uma ou outra nota no jornal, essa primeira exposição passou despercebida ${ }^{4}$. Foi o que aconteceu também com Lasar Segall (um artista lituano que fixou residência definitiva no país em 1923), cuja exposição de pinturas expressionistas de 1913 não provocou nenhuma reação (cf. BRITO, 1978, p. 29). Outro fato que precedeu a exposição de Anita foi o retorno de Oswald de Andrade da Europa em 1912, onde conhecera o Futurismo italiano, além do Cubismo na França. 
Antes de 1917, Anita Malfatti estivera nos Estados Unidos onde desenvolvera estudos de pintura com o professor e filósofo Homer Boss. Como ela própria conta, foi uma estadia de pura aventura cultural em que manteve contato com os mais avançados artistas da época, como: Máximo Gorki, Sergei Diaghilev, Isadora Duncan, Marcel Duchamp, e mais outros. Com o professor Boss, Anita aprendera a exercitar a pintura com extrema liberdade, ao tempo em que se familiarizava e produzia quadros com os elementos da arte cubista. "Eles [os artistas europeus refugiados da I Guerra] só falavam no cubismo, e nós de macaquice começamos a fazer as primeiras experiências" (BATISTA, 1972, p. 43). No retorno ao Brasil, por insistência das pessoas que viram seus quadros, a pintora decidiu fazer a Exposição que ficou em cartaz de dezembro de 1917 a janeiro de 1918. Mas esses trabalhos foram violentamente atacados por um crítico e escritor bastante influente, Monteiro Lobato, que qualificou a arte de Anita como um misto de "paranoia e mistificação": "Essas considerações são provocadas pela exposição da Sra. Anita Malfatti onde se notam acentuadíssimas tendências para uma atitude estética forçada no sentido das extravagâncias de Picasso e companhia" (BATISTA, 1972, p. 46).

No caso Anita, estão, pela primeira vez, defrontados publicamente no Brasil dois valores radicalmente distintos. Umé o valor representativo do conservadorismo cultural da época; as palavras de Monteiro Lobato reproduzem os parâmetros de uma estética acadêmica que entendia a pintura como reprodução direta da natureza. Outro é o valor absolutamente novo, expresso nos quadros de Anita, de uma arte que atende a seus próprios princípios, não tendo um compromisso fotográfico com os objetos da realidade natural.

Por essa exposição, a artista pagou um alto preço. Os quadros foram repudiados de todas as maneiras possíveis, e apenas Oswald de Andrade, cujo impulso inovador já se manifestava desde seu retorno da Europa, foi capaz de escrever um artigo em defesa de Anita. A clarividência de Oswald marcou um primeiro elo de ligação entre duas inteligências sintonizadas com a mesma atualidade artística. Mário de Andrade também visitou, mais de uma vez, essa exposição, chegando a dedicar um poema parnasiano ao quadro $O$ Homem amarelo. Pela primeira vez, o "relógio do império da cultura nacional" (Oswald) se deixava acertar pelo horário da vanguarda internacional. 
Entre 1917 e 1922, são cinco anos em que vários acontecimentos se vão somando numa espécie de fatalidade por vir. A partir da Exposição, Mário de Andrade se torna amigo de Anita Malfatti. Oswald de Andrade já conhecera Mário anteriormente, quando, em 21 de novembro de 1917, este fizera um pequeno discurso no Conservatório Musical, onde trabalhava. Muitos artigos, discussões e conferências serão realizados até surgir a ideia de se criar uma Semana de Arte Moderna.

\section{Os "futuristas" brasileiros}

Em 1920, o grupo divulgador das ideias modernas no Brasil recebe a designação genérica de "futurista", termo extraído da vanguarda italiana de Marinetti. De certo modo, "Futurismo" é a palavra que reúne toda a ideia de modernização de que estava carecendo a cultura nacional naquele momento. Um trecho do primeiro manifesto da estética futurista, de 1909, ajuda a apreender sua elaboração conceitual: "Admirar um velho quadro é verter nossa sensibilidade numa urna funerária, em vez de lançá-la adiante pelos jatos violentos da criação e ação" ${ }^{\prime \prime}$. O Futurismo de Marinetti é, portanto, essa tendência de negação da arte do passado; significando um corte violento na tradição, só interessava desenvolver uma estética análoga dos novos empreendimentos tecnológicos, numa direção exclusivamente prospectiva.

A atitude vanguardista daquele grupo admirador de Anita Malfatti fez com que fosse identificado ao ideário da escola futurista. Serão assim tratados como futuristas os artistas plásticos Victor Brecheret, Anita Malfatti, Vicente do Rego Monteiro, Di Cavalcanti e o suíço no Rio, John Graz, pela razão

5 Cf. TELES, Gilberto Mendonça (Org.). Vanguarda européia e modernismo brasileiro: apresentação e crítica dos principais manifestos vanguardistas (1983, p. 93). Este livro de Teles constitui uma referência sobre o assunto no Brasil. Para o contexto latino-americano, cf. SCHWARTZ, Jorge (Org.). Vanguardas latino-americanas: polêmicas, manifestos e textos críticos (1995). de trazerem elementos inovadores em suas obras (cf. BRITO, 1978, p. 162-163). Mas a aceitação do rótulo pelo próprio grupo não foi pacífica, apenas acontecendo depois de muita relutância, numa fase posterior do movimento.

É São Paulo que vai ser a fonte de inspiração e o assunto principal do segundo livro de poemas de Mário de Andrade, Pauliceia desvairada, escrito em 1921. E Pauliceia desvairada é esse primeiro livro radicalmente moderno. Nele, utilizam-se os recursos defendidos pelas artes de vanguarda europeia, principalmente o verso livre, com seu correlato nas "palavras em liberdade" de natureza futurista. Todavia, o ponto mais 
delicado do livro é exatamente sua vinculação à escola de Marinetti, a qual Mário de Andrade de pronto recusou.

\section{A ruptura da Semana de 22: sob vaias}

Segundo Mário de Andrade, a ideia da Semana de Arte Moderna pertence ao pintor Di Cavalcanti (mas essa atribuição não é pacífica, pois é feita também ao influente escritor Graça Aranha), o qual, chegando do Rio em outubro de 1921, comunicou-a aos companheiros (Cf. BATISTA, 1972, p. 74). Em suas memórias, Di confirma esse fato. A proposta era a de unir aos festejos do Centenário da Independência do Brasil, em 1922, o marco de outra independência, a da cultura brasileira, paradoxalmente sob inspiração das vanguardas estéticas europeias: a futurista, a cubista, a expressionista e a dadaísta.

Desse modo, em 29 de janeiro de 1922, o jornal O Estado de São Paulo anunciava a Semana de Arte Moderna, "por iniciativa do festejado escritor, Sr. Graça Aranha, da Academia Brasileira de Letras"' (BRITO, 1986, p. 17). A Semana constou de uma exposição de pintura de 13 a 18 de fevereiro de 1922, sendo que nos dias 13, 15 e 17 houve três espetáculos com atividades variadas: conferências, leituras de poemas, danças, recitais e concertos musicais. $\mathrm{O}$ festival de abertura teve a participação de Graça Aranha, com a conferência "A Emoção estética na arte moderna", pouco entendida pelo público. Seguiram-se números de música, poesia, piano e dança, além de outra conferência de Ronald de Carvalho, "A Pintura e a escultura moderna no Brasil".

Mas a grande noite foi a do dia 15, aberta por Menotti del Picchia que fez um discurso de teor justamente futurista. A confusão começou quando Menotti passou a apresentar os escritores que declamariam trechos de suas obras. Debaixo de uma "viva vaia" (título de um famoso poema concreto de Augusto de Campos) realizaram-se os espetáculos da Semana de Arte Moderna de 1922. Acontecera, enfim, aquilo que se estivera preparando desde o ano anterior, mas cuja construção vinha desde pelo menos a exposição de Anita Malfatti em 1917. Como disse Mário: “O modernismo, no Brasil, foi uma ruptura, foi um abandono de princípios e de técnicas consequentes, foi uma revolta contra o que era a Inteligência nacional" (ANDRADE, Mário de, 1974. p. 235). Portanto, a Semana de Arte 
Moderna de São Paulo foi o marco de ruptura do movimento de intelectuais que desestabilizou o sistema tradicional da cultura brasileira.

Num estudo que explora as relações dos intelectuais modernistas com a classe dirigente da época, isto é, com a oligarquia paulista, Sérgio Miceli afirma que

$\mathrm{O}$ acesso dos modernistas às frentes de vanguardas europeias por força de sua proximidade social junto aos círculos intelectualizados da oligarquia foi, paradoxalmente, a condição que lhes permitiu assumir o papel de inovadores culturais e estéticos no campo literário local, tomando a dianteira (MICELI, 1979, p. 15).

Parece que a explicação recai no fato de ter sempre interessado às classes dirigentes do Brasil a atualização com a última novidade europeia. Em vez de colocar a industrialização incipiente como fator de modernização cultural, é mais lógico ver nisso tudo um último esforço da oligarquia rural decadente, mas politicamente dominante, a fim de manter sua posição de superioridade para com os outros segmentos sociais. Essa razão se confirma com as palavras de Mário de Andrade, quando ele diz que "A aristocracia nos deu mão forte, pondo em evidência mais essa germinação de destino - também ela já então autofagicamente destruidora, por não ter mais uma significação legitimável" (ANDRADE, Mário de, 1974, p. 241).

\section{Oswald de Andrade e a Antropofagia "primitivista"}

A realização do projeto estético, por parte dos jovens modernistas, instalou uma carência a partir de 1922, pois faltava articulá-lo ao projeto ideológico, como sublinha João Luís Lafetá a respeito dos dois projetos que informaram o movimento modernista $^{6}$. Com a importação do Futurismo, do Cubismo, do Expressionismo, entre outros "ismos" europeus, reafirmavam-se mais uma vez as linhas de uma "dependência cultural". Ser futurista no Brasil diferia aparentemente muito pouco de o ser na Europa, por mais que se declarasse uma independência. Razão pela qual o Modernismo brasileiro carecia de um rosto próprio.

Em 1923, Oswald de Andrade viaja à Europa, passando a

6 Cf. LAFETÁ, João Luís. Os pressupostos básicos (1974, p. 11-23). travar contato direto com os movimentos europeus, Cubismo e Dadaísmo, sobretudo. E é em Paris "do alto de um atelier da 
Place Clichy - umbigo do mundo", segundo Paulo Prado, que ele "descobre o Brasil" (PRADO, 2003, p. 89. Grifos do autor). Independentemente da lenda, interessa que, por meio de uma das tendências da vanguarda europeia, se dá a compreensão do "que é brasileiro", irrompendo a força do nacional, a supor que uma tal identidade exista.

O traço da vanguarda, presente na obra de um Picasso e na de outros artistas cubistas, fauvistas e dadaístas, que provocou a "iluminação" parisiense de Oswald, foi o primitivismo. Assim como numa tela do pintor cubista exploravam-se elementos considerados primitivos, uma máscara africana, por exemplo, em Les Demoiselles d'Avignon, de Picasso, igualmente para o escritor brasileiro se tornava sugestiva a utilização de elementos populares da cultura nacional.

Importa, entretanto, observar que, do ponto de vista da cultura europeia, o elemento popular da cultura brasileira equivaleria ao elemento primitivo das culturas indígenas e africanas. Como diz Antonio Candido, "Ora, no Brasil, as culturas primitivas se misturam à vida cotidiana ou são reminiscências ainda vivas de um passado recente" (1976, p. 121).

Enquanto para o europeu, o primitivo era o exótico, o diferente da "cultura branca", a ser explorado, para nós isso era conatural de uma tradição. Mas foi com o olhar europeu, com essa forma de visão do outro desconhecido, que Oswald retornou ao Brasil.

O “Manifesto da Poesia Pau-Brasil”, de 1924, é uma consequência da necessidade de explorar o "primitivo" que orienta a nova disposição intelectual de Oswald de Andrade. O "pau-brasil", matéria-prima presente em toda a costa brasileira na época da invasão portuguesa, diz bem da ideologia implicada na atitude. Recito a fala de Oswald: "Temos a base dupla e presente - a floresta e a escola. A raça crédula e dualista e a geometria, a álgebra e a química logo depois da mamadeira e do chá de erva doce. Um misto de 'dorme nenê que o bicho vem pegá' e de equações" (ANDRADE, Oswald de, 1995, p. 44).

Todavia, é apenas com o "Manifesto Antropófago" de 1928, que Oswald vai descobrir a possibilidade de pensar as diferenças da cultura brasileira como um valor em si mesmo, não mais a ser avalizado pelo europeu como produto de exportação. “Só a antropofagia nos une. Socialmente. Economicamente. Filosoficamente" (ANDRADE, Oswald de, 1995, p. 47), são essas 
as primeiras palavras do manifesto. Logo, assim define-se o traço de nacionalidade brasileira, o ser antropófago. Em todos os níveis, nossa cultura teria sido feita, certamente desde o Descobrimento, do deglutir a cultura alheia, "Só me interessa o que não é meu. Lei do homem. Lei do antropófago" (ANDRADE, Oswald de, 1995, p. 47).

Retornava então com o antropofagismo, em sua plena força e sem mediações, aquilo que desde o início representou o elemento autóctone das terras brasileiras. "O que é brasileiro", irredutível a qualquer outra cultura ou nacionalidade, é ser tupy (índio), eis nossa questão ("Tupi or not tupi, that is the question", parodia Oswald a famosa frase do Hamlet - 1995, p. 47). A catequese pretendida pelo europeu foi apenas um engodo do aborígene para poder fazer sua festa particular com a cultura do outro (cf. SANTIAGO, 1982, p. 16-17).

É bastante provável que Oswald, em sua visita à Europa, tenha canibalizado o Manifeste Cannibale Dada, de Picabia - publicado em março de 1920, em Dadaphone -, e a revista de mesmo nome, Cannibale, que contou com dois números, publicados em abril e maio nesse mesmo ano. Há sem dúvida pontos de contato entre as ideias do dadaísta francês e as do modernista brasileiro. Creio que a maior convergência entre o vanguardista europeu e o tropical é a irreverência contra a cultura burguesa ocidental. Em ambos, encontra-se a contestação da ordem social vigente, com o imperativo de épater le bourgeois. No caso do artista Dada, atinge-se o niilismo, mas não sem autoironia, como se pode ver no seguinte trecho do Manifesto:

[...]

L'honneur s'achète et se vend comme le oui. Le cul, le cul représente la vie représente la vie comme les pommes frites, et vous tous qui êtes sérieux, vous sentirez plus mauvais que la merde de vache.

DADA lui ne sent rien, il n'est rien, rien, rien.

Il est comme vos espoirs: rien

comme vos paradis: rien

comme vos idoles: rien

comme vos hommes politiques: rien

comme vos héros: rien

comme vos artistes: rien

comme vos religions: rien 
Sifflez, criez, cassez-moi la gueule et puis et puis? Je vous dirai encore que vous êtes tous des poires. Dans trois mois, nous vous vendrons, mes amis et moi, nos tableaux pour quelques francs (PICABIA, 2012).

Todavia, Dawn Ades, no ensaio bastante esclarecedor, "As Dimensões antropofágicas do dadá e do surrealismo", considera que um traço diferencia a atitude dadaísta dos outros movimentos de vanguarda: Dada é tão radical que se quer antimoderno, no fundo antitudo. Comenta o estudioso:

\begin{abstract}
É possível que as conotações primitivas de "canibal" [associadas ao título do manifesto Cannibale] fossem uma referência irônica tanto às reivindicações dos futuristas que se pretendiam "primitivos de uma nova sensibilidade", como às pinturas africanizadas e pré-cubistas de Picasso. É claro que, até certo ponto, o dadá teve participação na vertente primitivista do modernismo, particularmente quando podia servir à utilização polêmica contra sua própria civilização falida. Entretanto o dadá não se dizia parte da vanguarda modernista; ("Dadá não é moderno", insistia). Seu senso da inadequação das "escolas de ideias formais" como tais, e para seus propósitos, revela um dos impulsos subjacentes ao dadá: o de restabelecer uma imediação para a arte, uma relação direta com a vida (ADES, 1998, p. 236).
\end{abstract}

Em outros termos: Dadá era profundamente niilista no que diz respeito à oficialidade artística e cultural, por ser descrente de tudo. Já a Antropofagia oswaldiana, que foi apresentada a Albert Camus quando este visitou o Brasil entre julho e agosto de 1949, só detinha um dos sentidos da palavra niilismo, como definida por Nietzsche: o afirmativo. Atravessado por inspiração psicanalítica, Freud sendo aí um de seus principais "deglutidos", o "Manifesto Antropófago" desejava trazer esse grande desrecalque, em que cada um de nós tirasse sua roupa e vestisse tanga e colar, transformando enfim o tabu das civilizações no totem de uma cultura "primitiva" que se quer primitiva, isto é, no sentido tópico da palavra, antes de certo tipo de civilização, no caso, a invasão europeia nos trópicos.

Se podem ser aceitas as teses do "branco" Pierre Clastres, no clássico La Société contre l'état (1974), sobre a organização política das culturas ameríndias, nas quais se encontra, como 
em nenhum outro lugar do mundo, uma sociedade plena em seus poderes, vivendo independente e contra o Estado, entende-se igualmente a alegria antropofágica de Oswald de Andrade ao afirmar o primado de Pindorama. Em vez do Patriarcado político, haveria uma Mãe social, na terra de Piratininga7.

Sublinho o fato de que o sentido do chamado primitivismo se altera para cada um dos movimentos e seus atores. Antes de Dada, o "primitivismo" detém, sobretudo, um viés estetizante, no caso do fauvismo, sendo até mesmo decorativo. Já para o canibal Picabia, como visto, era uma questão de levar à derrisão os outros movimentos vanguardistas, bem como toda a cultura a que se relacionava naquele momento de pós $1^{\text {a }}$. Guerra Mundial.

Segundo Gill Perry, um dos autores de Primitivismo, cubismo, abstração,

O apelo dos objetos africanos e da Oceania para os fauves tinha raízes nos mesmos interesses e pressupostos que embasavam o apelo da obra de Gauguin para o grupo. Eles significavam o exótico ou o "primitivo", redefinido de acordo com um código artístico de vanguarda ocidental. Além do mais, a ausência de uma iconografia ou uma história acessíveis desses objetos permitia que eles fossem facilmente absorvidos numa cultura artística moderna. Essa descontextualização é uma das várias razões pelas quais os artistas modernos foram acusados de responder de modo etnocentrista à arte africana e da Oceania, atribuindo a suas aparências (significantes) sentidos ocidentais do século XX (significados) (PERRY, 1998, p. 56).

Philippe Dagen, um dos grandes historiadores da questão "primitiva", expõe a complexidade da influência de Gauguin sobre as gerações seguintes de artistas. Sublinhando em particular a geração de Henri Matisse, André Derain e Pablo Picasso, Dagen demonstra como a influência não era apenas formal, mas amplamente ideativa, para não dizer ideológica:

7 A relação entre o estudo de Clastres e a antropofagia de Oswald foi sugerida por Silviano Santiago em 1985, num curso de extensão universitária.
[...] malgrado as tentativas de alguns analistas do primitivismo, do fauvismo e dos primórdios do cubismo, a análise do gauguinismo da vanguarda não pode se restringir a considerações formais - círculos, demãos, deformações, esquematismos. [...] o mito do civilizado em busca de uma idade do ouro na Oceania foi amplamente difundido e comentado (DAGEN,2010, p. 258). 
Já para Oswald, a Antropofagia significou um tipo de redefinição da cultura brasileira em face da cultura-matriz europeia, num movimento de autêntica independência por meio de um "primitivo" bem brasileiro. Tal como se pode visualizar numa tela hoje clássica de Tarsila do Amaral, esse "primitivo" era o Antropófago (Abaporu, título em tupi-guarani, tal como ficou conhecida essa obra de 1928). Com a Antropofagia, parece que Oswald de Andrade, pelo caminho torto da vanguarda europeia, através dessa curva transatlântica que passa por Paris e volta ao Brasil, solucionou o paradoxo de ser um irreverente representante da classe dominante, redescobrindo, enfim, o nacional popular. O capítulo seguinte dessa história é o ingresso do poeta-antropófago no partido comunista.

O exemplo excepcional de Oswald de Andrade sugere, muito provavelmente, o caminho para reavaliar as relações culturais entre Brasil e Europa. Muito além da influência passiva, sem alterações, desfere-se o golpe da ruminação antropófaga, glutona, digerindo e repetindo o elemento estrangeiro, porém inscrevendo-lhe o traço da diferença. Nisso, é toda uma determinação entre dominador e dominado que se vê abalada como um todo, quando o "selvagem" faz o "civilizado" escrever, levando-o a ver o que ele não poderia ter visto e consequentemente dito, por motivos de etnocentrismo. ${ }^{8}$

\section{REFERÊNCIAS}

ADES, Dawn. As Dimensões antropofágicas do dadá e do surrealismo. In: Fundação Bienal de São Paulo. XXIV Bienal de São Paulo: núcleo histórico - Antropofagia e histórias de canibalismos. São Paulo: Fundação Bienal de São Paulo, 1998. p. 234-240.

8 Num ensaio de 2006, republicado com modificações em 2011, faço uma revisão bastante crítica acerca do legado da Antropofagia oswaldiana. Cf. NASCIMENTO, 2011. Para uma visão global do assunto, cf. olivro de JÁUREGUI, Carlos. Canibalia: canibalismo, calibanismo, antropofagia cultural y consumo en América Latina. (2005).

ANDRADE, Mário de. O movimento modernista. In: Aspectos da literatura brasileira. São Paulo: Martins, 1974. p. 231-262. ANDRADE, Oswald de. Manifesto antropófago. In: A utopia antropofágica. 2a. ed. São Paulo: Globo, 1995. p. 47-52. . Manifesto da Poesia Pau Brasil. In: . A utopia antropofágica. 2a . ed. São Paulo: Globo, 1995. p. 41-45. BATISTA, M. R. et alii. Brasil: $1^{\circ}$ tempo modernista - 1917/1926; documentação. São Paulo: USP-IEB, 1972. 
BOSI, Alfredo. História concisa da literatura brasileira. São Paulo: Cultrix, 1979.

BRITO, Mário da Silva. História do modernismo brasileiro: antecedentes da Semana de Arte Moderna. Rio de Janeiro: Civilização Brasileira, 1978.

. A revolução modernista. In: COUTINHO, Afrânio (Dir.); COUTINHO, Eduardo (Co-dir.). A literatura no Brasil: era modernista. v. 5. Rio de Janeiro: José Olympio, 1986, p. 4-42.

CANDIDO, Antonio. Literatura e cultura de 1900 a 1945. In: . Literatura e sociedade. São Paulo: Companhia Editora Nacional, 1976. p. 109-138.

CLASTRES, Pierre. La Société contre l'État. Paris: Minuit, 1974. CUNHA, Euclides da. Hautes terres: La Guerre de Canudos. Tradução J. Coli e A. Seel. Paris: Métailié, 2012.

DAGEN, Philippe Dagen. Le Peintre, le poète, le sauvage: les voies du primitivisme dans l'art français. Paris: Champs Arts, 2010. FAUSTO, Boris. História da civilização brasileira: o Brasil republicano (sociedade e instituições), v. 3. Rio de Janeiro: Difel, 1975.

FERRO, Marc. Histoire des colonisations: des conquêtes aux indépendances XIIIe.-XXe. Siècle. Paris: Seuil, 1994.

GONÇALVES, Marcos Augusto. 1922: a semana que não terminou. São Paulo: Companhia das Letras, 2012.

JÁUREGUI, Carlos. Canibalia: canibalismo, calibanismo, antropofagia cultural y consumo en América Latina. La Habana: Casa de las Américas, 2005

LAFETÁ, João Luiz. Os pressupostos básicos. In: .1930: a crítica e o modernismo. São Paulo: Duas Cidades, 1974. p. 11-27. LAJOLO, Marisa. Usos e abusos da literatura na escola: Bilac e a literatura escolar na República Velha. Rio de Janeiro: Globo, 1982.

MICELI, Sérgio. Intelectuais e classe dirigente no Brasil: (1920 1945). São Paulo: Difel, 1979.

NASCIMENTO, Evando. A Antropofagia em questão. In: RUFINELLI, Jorge Rufinelli; ROCHA, João Cezar de Castro (Org.). Antropofagia hoje? Oswald de Andrade em cena. São Paulo: É Realizações, 2011, p. 331-361. 
PERRY, Gill. O primitivismo e o "moderno". In: HARRISON, Charles; FRASCINA, Francis; PERRY, Gill. Primitivismo, cubismo, abstração: começo do século XX. Tradução Otacílio Nunes. São Paulo: Cosac \&Naify, 1998.

PICABIA, Francis. Manifeste Cannibale Dada. Dada $n^{\circ} 7$ DADAphone, Paris, março de 1920. Disponível em: < http:// sdrc.lib.uiowa.edu/dada/dada/7/images/02.pdf $>$. Acessado em: 2 mai. 2012.

PRADO, Paulo. Poesia Pau Brasil. In: ANDRADE, Oswald de. Pau Brasil: poesias completas. 2a . ed. São Paulo: Globo, 2003,p. 89-94. RUFIN, Jean-Cristophe. Rouge Brésil. Paris: Gallimard, 2003. SANTIAGO, Silviano. Calidoscópio de questões. In: TOLIPAN, S. et alii. Sete ensaios sobre o modernismo. Rio de Janeiro: FUNARTE, 1983. . Fechado para balanço: 60 anos de modernismo. Rio de Janeiro: PUC - Divisão de Intercâmbio e Edições, 1982. Mimeogr.

TELES, Gilberto Mendonça. Vanguarda européia e modernismo brasileiro: apresentação e crítica dos principais manifestos vanguardistas. Petrópolis: Vozes, 1983.

TOLIPAN, S. et alii. Sete ensaios sobre o modernismo. Rio de Janeiro: FUNARTE, 1983.

SCHWARTZ, Jorge (Org.). Vanguardas latino-americanas: polêmicas, manifestos e textos críticos. São Paulo: Iluminuras : FAPESP : EdUSP, 1995. 


\section{Abstract}

Modern Art Week of 1922 and Brazilian modernism: cultural updating and artistic "primitivism"

Ninety years after the Modern Art Week of 1922, which took place in São Paulo, this text discusses its relationship with European avant-gardes. It emphasizes the esthetical and political projects of the Brazilian modernism, and, finally, it brings into light the link between one of the aspects of the Brazilian modernist movement, Anthropophagy, and the European esthetical and cultural "primitivism", in such movements such as Fauvism and Dada.

Keywords: Modern Art Week of 1922, Mário de Andrade, Oswald de Andrade, Anthropophagy, Primitivism 